\title{
The Anorexigenic Neuropeptide, Nesfatin-1, Is Indispensable for Normal Puberty Onset in the Female Rat
}

\author{
David García-Galiano, ${ }^{1,2}$ Víctor M. Navarro, ${ }^{1,2}$ Juan Roa, ${ }^{1,2}$ Francisco Ruiz-Pino, ${ }^{1,2}$ Miguel Angel Sánchez-Garrido, ${ }^{1,2}$ \\ Rafael Pineda, ${ }^{1,2}$ Juan Manuel Castellano, ${ }^{1,2}$ Magdalena Romero, ${ }^{1,2}$ Enrique Aguilar, ${ }^{1,2,3}$ Francisco Gaytán, ${ }^{1,2}$ \\ Carlos Diéguez, ${ }^{2,4}$ Leonor Pinilla, ${ }^{1,2}$ and Manuel Tena-Sempere ${ }^{1,2,3}$ \\ ${ }^{1}$ Department of Cell Biology, Physiology and Immunology, University of Córdoba, ${ }^{2}$ Centro de Investigación Biomédica en Red Fisiopatología de la Obesidad \\ y Nutrición, and ${ }^{3}$ Instituto Maimónides de Investigaciones Biomédicas, 14004 Córdoba, Spain, and ${ }^{4}$ Department of Physiology, University of Santiago de \\ Compostela, 15705 Santiago de Compostela, Spain
}

The hypothalamic peptide, nesfatin-1, derived from the precursor NEFA/nucleobindin 2 (NUCB2), was recently identified as anorexigenic signal, acting in a leptin-independent manner. Yet its participation in the regulation of other biological functions gated by body energy status remains unexplored. We show herein that NUCB2/nesfatin-1 is involved in the control of female puberty. NUCB2/nesfatin mRNA and protein were detected at the hypothalamus of pubertal female rats, with prominent signals at lateral hypothalamus (LHA), paraventricular (PVN), and supraoptic (SON) nuclei. Hypothalamic NUCB2 expression raised along pubertal transition, with detectable elevations of its mRNA levels at LHA, PVN, and SON, and threefold increase of its total protein content between late-infantile and peripubertal periods. Conditions of negative energy balance, such as $48 \mathrm{~h}$ fasting or sustained subnutrition, decreased hypothalamic NUCB2 mRNA and/or protein levels in pubertal females. At this age, central administration of nesfatin- 1 induced modest but significant elevations of circulating gonadotropins, whose magnitude was notably augmented in conditions of food deprivation. Continuous intracerebroventricular infusion of antisense morpholino oligonucleotides (as-MONs) against NUCB2 along pubertal maturation, which markedly reduced hypothalamic NUCB2 protein content, delayed vaginal opening and decreased ovarian weights and serum luteinizing hormone (LH) levels. In contrast, in adult female rats, intracerebroventricular injection of nesfatin did not stimulate $\mathrm{LH}$ or folliclestimulating hormone secretion; neither did central as-MON infusion alter preovulatory gonadotropin surges, despite suppression of hypothalamic NUCB2. In sum, our data are the first to disclose the indispensable role of NUCB2/nesfatin-1 in the central networks driving puberty onset, a function that may contribute to its functional coupling to energy homeostasis.

\section{Introduction}

Food intake and body energy homeostasis are regulated, at the hypothalamus and other CNS areas, by a complex neuronal network involving different neuropeptides and transmitters, with orexigenic or anorexigenic actions (Kalra et al., 1999; Berthoud and Morrison, 2008; Crowley, 2008; Woods and D'Alessio, 2008). In the search for appetite-regulating molecules, nesfatin-1 was recently identified as an 82 aa neuropeptide, cleaved out from the N-terminal region of NEFA/nucleobindin 2 (NUCB2), a 396 aa precursor protein of otherwise poorly characterized functions (Oh-I et al., 2006). Compelling evidence suggests that nesfatin-1 is involved in the central control of food intake, acting as anorectic molecule (Myers, 2006; Oh-I et al., 2006; Colmers, 2007). Expression of NUCB2 mRNA and/or protein has been demon-

\footnotetext{
Received Nov. 24, 2009; revised March 18, 2010; accepted April 15, 2010.

This work was supported by Ministerio de Ciencia e Innovación (Spain) Grants BFU 2005-07446 and BFU 200800984, Ministerio de Sanidad (Spain) Project PI042082, Junta de Andalucía (Spain) Project P08-CVI-03788, and European Union Research Contract DEER FP7-ENV-2007-1. Centro de Investigación Biomédica en Red Fisiopatología de la Obesidad y Nutrición is an initiative of Instituto de Salud Carlos III, Ministerio de Sanidad, Spain.

Correspondence should be addressed to Manuel Tena-Sempere, Physiology Section, Department of Cell Biology Physiology and Immunology, Faculty of Medicine, University of Córdoba, Avenida Menéndez Pidal s/n, 14004 Córdoba, Spain. E-mail: fi1tesem@uco.es.

D0I:10.1523/JNEUROSC1.5828-09.2010

Copyright $\odot 2010$ the authors $\quad 0270-6474 / 10 / 307783-10 \$ 15.00 / 0$
}

strated in several hypothalamic nuclei, such as arcuate (ARC), paraventricular nucleus (PVN/PVH), and lateral hypothalamus (LHA), as well as in brainstem areas, as the nucleus of the solitary tract, with pivotal roles in regulation of feeding (Oh-I et al., 2006; Brailoiu et al., 2007; Foo et al., 2008; Kohno et al., 2008; Maejima et al., 2009). In addition, colocalization of NUCB2/ nesfatin- 1 and key neuropeptide regulators of appetite, such as POMC (proopiomelanocortin), cocaine- and amphetamineregulated transcript (CART), or melanin concentrating hormone (MCH) (Brailoiu et al., 2007; Foo et al., 2008; Fort et al., 2008), has been described, and close appositions and regulation between Neuropeptide Y (NPY) fibers and NUCB2 neurons have been shown (Price et al., 2008). Likewise, a recent report documented that nesfatin-1 stimulates oxytocin release at PVN as mechanism for its anorectic effects (Maejima et al., 2009).

Functional tests have demonstrated that cerebral injection of nesfatin-1, but not of the other peptide fragments of NUCB2 (nesfatin-2 and nesfatin-3), inhibits food intake (Oh-I et al., 2006; Shimizu et al., 2009), whereas blockade of NUCB2/nesfatin expression or actions enhances feeding in adult rats (Oh-I et al., 2006). Although the mechanisms of action of nesfatin-1 remain to date ill defined, in part because of the fact that its putative receptor has not been cloned yet, it has been proposed that its anorectic effect is not dependent on leptin (Oh-I et al., 2006; 
Shimizu et al., 2009), but rather related with the modulation of melanocortin, CART, MCH, and/or NPY pathways (Foo et al., 2008; Fort et al., 2008; Price et al., 2008; Shimizu et al., 2009). This feature has drawn quite some interest, as situations of leptin resistance, commonly associated with obesity, might still benefit from pharmacological treatment with nesfatin (Oh-I et al., 2006; Shimizu et al., 2009).

As a reflection of the intimate connection between the energy status and other essential body functions, extensive cross talk between appetite-regulating molecules and several neuroendocrine systems has been disclosed in recent years (FernandezFernandez et al., 2006; Hill et al., 2008). However, potential functions of nesfatin-1 other than the control of feeding remain poorly defined, and its putative role in the metabolic gating of other relevant neurohormonal systems has not been thoroughly explored (Foo et al., 2008; Goebel et al., 2009; Stengel et al., 2009; Yosten and Samson, 2009). Concerning metabolic regulation, it is well known that the onset and maintenance of reproductive function critically depends on proper fuel reserves, a phenomenon that relies on a complex regulatory network of central and peripheral signals in which the adipose hormone, leptin, has been proven as an essential player (Fernandez-Fernandez et al., 2006; Hill et al., 2008; Castellano et al., 2009a). Other metabolic hormones are likely to cooperate also in this function (FernandezFernandez et al., 2006). Yet the (central) transmitting signals and integrator pathways for such metabolic regulators of reproduction remain to date mostly unknown.

In this work, we aimed to determine whether NUCB2/ nesfatin-1 participates in the central control of the gonadotropic axis at puberty. To this end, expression analyses and functional tests were conducted in female rats. As our data evidenced the role of nesfatin-1 as putative regulator of female puberty, additional experimental work was undertaken to evaluate the potential role of this neuropeptide in the control of gonadotropin secretion, and specifically of the preovulatory surges, in the adult female.

\section{Materials and Methods}

Wistar female rats, bred in the vivarium of the University of Córdoba, were used. Experimental procedures were approved by the Córdoba University Ethical Committee and conducted in accordance with the European Union normative for use of experimental animals. Rat nesfatin-1 (1-82) was purchased from Phoenix Pharmaceuticals. For expression analyses involving reverse transcription (RT)-PCR or Western blot, hypothalami were dissected out, immediately on decapitation of the animals, by a horizontal cut $\sim 2 \mathrm{~mm}$ in depth with the following limits: 1 $\mathrm{mm}$ anteriorly from the optic chiasm, the posterior border of mamillary bodies, and the hypothalamic fissures (Navarro et al., 2004a; Castellano et al., 2005). The tissues were frozen in liquid nitrogen and stored at $-80^{\circ} \mathrm{C}$ until used for RNA or protein isolation. Tissue collection for in situ hybridization (ISH) and immunocytochemical analyses was conducted as described in following sections. For intracerebral injection of compounds, standard procedures of cannulation of the lateral cerebral ventricle, followed by acute or chronic intracerebroventricular administration, were implemented, using previously published protocols (Navarro et al., 2004a; Castellano et al., 2005, 2006; Roa et al., 2008c).

Experimental designs. As a mean to provide a morphological substrate for subsequent functional studies, the anatomical distribution of NUCB2/nesfatin at the hypothalamus was first explored, at the mRNA and protein levels, in peripubertal female rats, 35-d-old rats being consistently used as representative of this developmental stage, in keeping with our previous studies (Navarro et al., 2004b; Castellano et al., 2005; Roa et al., 2009). Thus, in experiment 1 , groups of 35 -d-old female rats $(n=5-6)$ were killed, and their brains were immediately excised and processed for ISH or immunocytochemistry (ICC), as described in specific sections below.

On the basis of this neuroanatomical information, in the second set of experiments, regulation of hypothalamic expression of NUCB2 by developmental and metabolic cues was explored at the time of puberty. First, in experiment 2 , groups of female rats $(n=8 /$ age), at the late-infantile (20-d-old) and peripubertal (35-d-old) stages of postnatal maturation, were decapitated and hypothalami were obtained and stored at $-80^{\circ} \mathrm{C}$ for RT-PCR assays. Additional groups of female rats $(n=5-6)$ were also killed at these developmental stages, and their brains were collected for in situ hybridization, as described below. In addition, in experiment 3, groups of pubertal (33-d-old) female rats ( $n=8$ /group) were submitted to $48 \mathrm{~h}$ of complete food deprivation; pair-aged females fed ad libitum served as controls. The animals were decapitated on day 35 , when the hypothalami were excised as described above. Again, additional wholebrain sections $(n=5-6)$ were also obtained from the same experimental groups in order to perform in situ hybridization. Finally, in experiment 4, the impact of chronic subnutrition along puberty on the expression of NUCB2 was monitored. To avoid the confounding factor of fluctuations in circulating estrogens caused by persistent undernutrition, and its potential impact on NUCB2 expression, these experiments were conducted in ovariectomized (OVX) rats. Thus, groups of females $(n=8-10)$ were OVX on day 28 and subjected to a protocol of $25 \%$ reduction in daily food intake from day 30 onward. The experiment was terminated on day 36 , when animals were decapitated and hypothalami dissected out for RNA/protein analyses.

In the third set of studies, the effects of nesfatin-1 on gonadotropin secretion were assessed in pubertal female rats. In experiment 5 , groups $(n=10-12)$ of pubertal (35-d-old) female rats were intracerebroventricularly injected with a single bolus of nesfatin- 1 at a dose (50 pmol/rat) that has been previously proven as biologically active in adult rats (Oh-I et al., 2006). Blood samples were taken by jugular venipuncture 15 and 60 min after intracerebroventricular injection of nesfatin-1. Animals intracerebroventricularly injected with vehicle (physiological saline; $5 \mu \mathrm{l}$ ) served as controls. In addition, given the impact of negative energy balance on the hypothalamic expression of NUCB2 documented in initial experiments, the effects of nesfatin-1 on gonadotropin secretion were also explored after short-term fasting. Thus, in experiment 6 , groups of pubertal (33-d-old) female rats $(n=10-12$ /group) were submitted to $48 \mathrm{~h}$ of complete food deprivation; females fed ad libitum were used as controls. On day 35 , the animals were subjected to intracerebroventricular administration of nesfatin-1 ( $50 \mathrm{pmol} / \mathrm{rat})$, followed by serial blood sampling for gonadotropin measurement, as described for experiment 5.

To determine the functional relevance of NUCB2/nesfatin-1 signaling in the control of gonadotropic axis and puberty onset in the female, in experiment 7, a protocol of disruption of central NUCB2 expression using antisense morpholino oligonucleotides (as-MONs) was implemented, following previous references (Oh-I et al., 2006). To allow central delivery of the oligonucleotides, the animals were implanted intradermally with osmotic minipumps $(1 \mu \mathrm{l} / \mathrm{h}$ delivery rate times $7 \mathrm{~d}$; Alzet miniosmotic pump model 2001; Durect) that were connected to intracerebroventricular cannulae. Concentration of as-MONs per minipump was adjusted to $40 \mu \mathrm{g} / 24 \mu \mathrm{l}$, in saline. The treatment spanned from postnatal day 28 to day 35 . Two different as-MONs were tested (MON-Ref and MON-UCO; $n=7$ /group); pair-aged females infused with a scrambled oligonucleotide sequence ( $n=8$ /group) served as controls. Along treatment, the animals were monitored for daily food intake, body weight (BW) gain, and vaginal opening. On day 35, the animals were killed by decapitation, trunk blood was collected, and tissues were dissected out and collected for protein analysis (hypothalamus) or weight (ovary, uterus) recording.

For comparative purposes, the potential role of central NUCB2/ nesfatin-1 signaling in the control of the female gonadotropic axis was also explored in adulthood. In this set of experiments, adult, virgin female rats, with at least two consecutive regular $4 \mathrm{~d}$ estrous cycles (as evidenced by daily vaginal cytology), were used. In experiment 8 , groups $(n=10-12)$ of adult $(>65$-d-old) female rats were intracerebroventricularly injected with a single bolus ( $50 \mathrm{pmol} / \mathrm{rat}$ ) of nesfatin- 1 , and blood sampling was conducted at 15 and $60 \mathrm{~min}$ after injection of the 

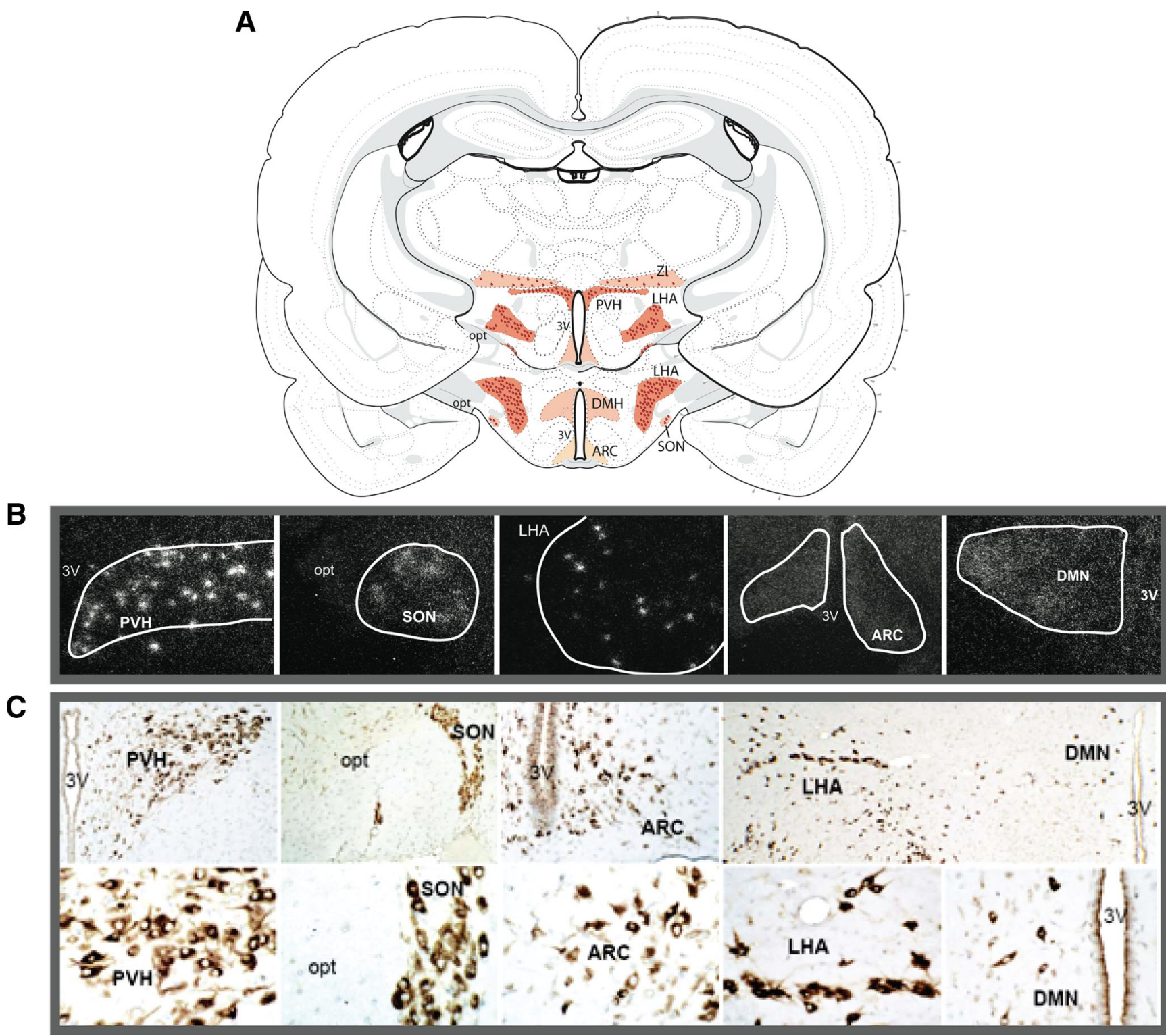

Figure 1. Neuroanatomical distribution of NUCB2 mRNA and prepro-nesfatin in the hypothalamus at puberty. The distribution of NUCB2 mRNA (detected by ISH) and prepro-nesfatin (detected by ICC) at the hypothalamus of pubertal (35-d-old) female rats is schematically represented in $A$. The most prominent RNA/protein signals were detected at the LHA, PVH, Zl, and SON. In addition, fainter NUCB2 mRNA grains were observed at the DMN and the ARC, although no discernible cell clusters could be detected at these sites. Representative photomicrographs of NUCB2 mRNA expression at these nuclei are presented in $\boldsymbol{B}$. In addition, representative images of neurons displaying clear nesfatin immunoreactivity in the above nuclei/areas are shown, at two different magnifications, in C. 3V, Third ventricle; opt, optic nerve.

peptide or vehicle. To avoid the potential confounding factor of changes in gonadotropin levels in adult females across the estrous cycle, hormonal tests were conducted in the morning of metestrus. In addition, in experiment 9, a similar experimental protocol was applied to groups of adult, cyclic female rats ( $n=10-12 /$ group) that were submitted to $48 \mathrm{~h}$ of complete food deprivation before hormone testing; intracerebroventricular administration of nesfatin-1 and serial blood sampling for gonadotropin measurements were as described for experiment 8 . Finally, in experiment 10, the impact of knocking down hypothalamic NUCB2 levels was explored in adult female rats, taking the preovulatory luteinizing hormone ( $\mathrm{LH}$ ) and follicle-stimulating hormone (FSH) surges of as surrogate marker of gonadotropic function in cyclic animals. A protocol of central infusion of MON-UCO, similar to that of experiment 7, was implemented in adult, virgin female rats; infusion was commenced in the morning of metestrus and continued for two consecutive cycles. During this period, the animals were subjected to blood sampling at each of afternoon/evening of proestrus (referred to as proestrus 1 and protestrus 2), following previously published protocols (Roa et al., 2008b,d). To minimize the number of hormone determinations, blood sampling was conducted at 1:00 P.M. and 6:00 P.M. of proestrus 1 (i.e., day 3 of infusion) and at 1:00 P.M., 6:00 P.M., and 8:00 P.M. of proestrus 2 (i.e., day 7 of infusion). Along treatment, the animals were monitored for daily food intake, BW gain, and estrous cyclicity. At the end of the experiment, the animals were killed by decapitation and tissues were dissected out and collected for protein analysis (hypothalamus) or weight (ovary, uterus) recording.

RNA analysis by semiquantitative RT-PCR. Total RNA was isolated from hypothalamic samples using the TRIsure reagent (Bioline), following the instructions of the manufacturer. NUCB2 mRNA levels were assayed by RT-PCR, optimized for semiquantitative (semiQ) detection, using the following primer pair: $r N e f$-forward ( $5^{\prime}$-GAG GAG ATA AGG AGC GGG AGG C-3'); rNef-reverse (5'-ATG TGT CAG GAT TCT GGT GGT TCA-3'); amplicon size, $208 \mathrm{bp}$. General procedures for RT and PCR were as described previously. Cycling PCR conditions consisted in a first denaturing cycle at $97^{\circ} \mathrm{C}$ for $5 \mathrm{~min}$, followed by 25 cycles of amplification, defined by denaturation at $96^{\circ} \mathrm{C}$ for $30 \mathrm{~s}$, annealing at $63^{\circ} \mathrm{C}$ for 
A

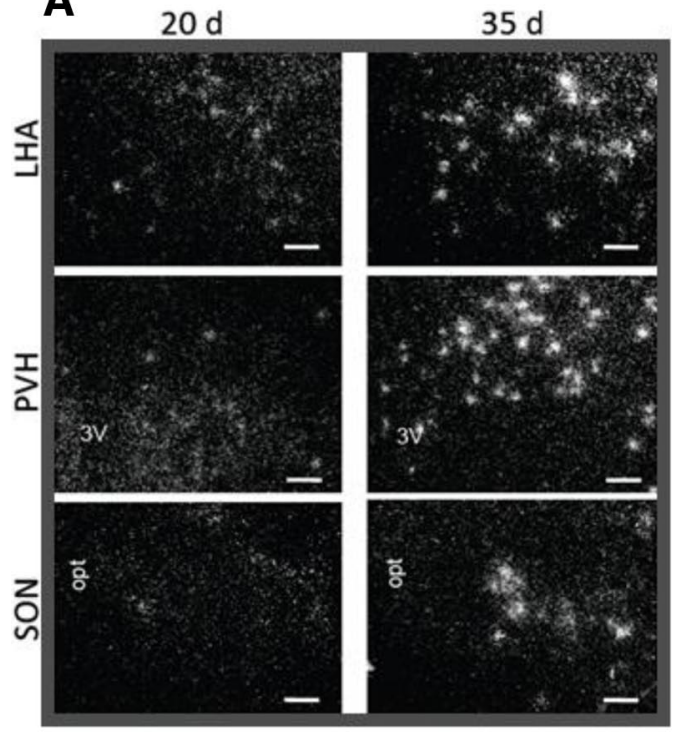

B
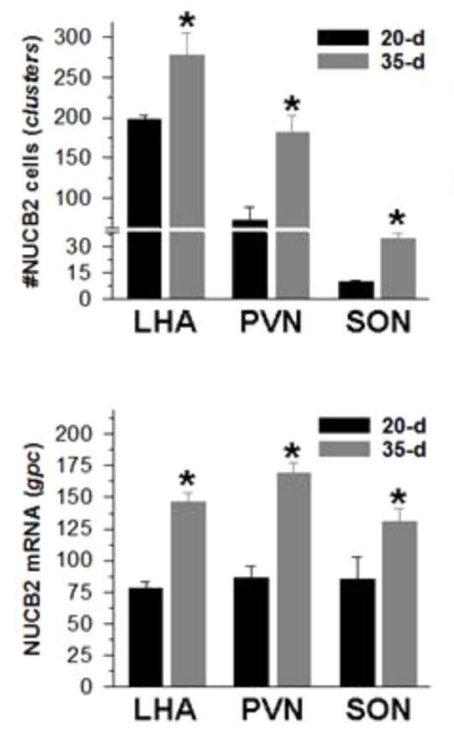

C
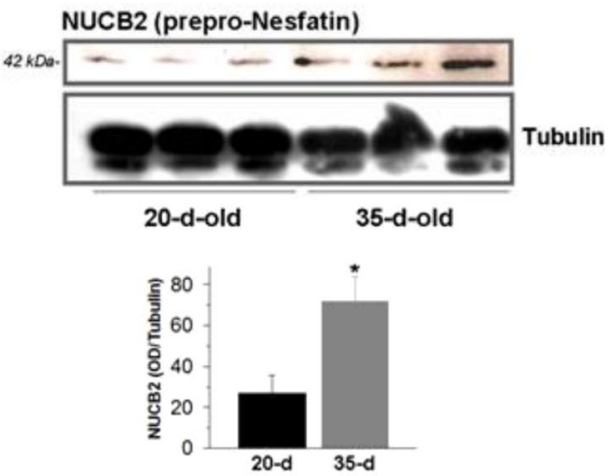

Figure 2. Developmental regulation of hypothalamic NUCB2 expression along puberty. In $\boldsymbol{A}$, ISH analyses of NUCB2 mRNA levels at LHA, PVN, and SON at two stages of postnatal sexual maturation: late-infantile (20 d of age) and peripubertal ( $35 \mathrm{~d}$ of age); representative photomicrographs of these nuclei at the two age points are presented. In addition, quantitative data, including counting of total number of cells (clusters) and the number of silver grains per cell (gpc) for each nuclei and age point, are presented as mean \pm SEM in $\boldsymbol{B}$. Finally, in $\mathbf{C}$, hypothalamic NUCB2 protein levels in the above developmental stages are shown, with representative Western blots and semi $Q$ data being included. * $p \leq 0.05$ versus 20 - $d$-old group (Student's $t$ test). Scale bars, $50 \mu \mathrm{m}$.

$30 \mathrm{~s}$, and extension at $72^{\circ} \mathrm{C}$ for $1 \mathrm{~min}$. A final extension cycle of $72^{\circ} \mathrm{C}$ for 10 min was included. The number of PCR cycles was defined at optimization assays, as to allow amplification within the exponential phase (strong linear relationship between NUCB2 signal intensity and PCR cycles was detected between cycles 21-33, with a correlation coefficient $r^{2}=0.996$ ), thus supporting the semiQ quantitative nature of our measurements. As internal control, amplification of a $240 \mathrm{bp}$ fragment of S11 ribosomal protein mRNA was performed in parallel in each sample, as described previously (Navarro et al., 2004a; Castellano et al., 2005). Specificity of PCR products was confirmed by direct sequencing. Quantification of intensity of RT-PCR signals was performed by densitometric scanning using an image analysis system (1-D Manager; TDI), and values of the specific target were normalized to those of internal controls to express arbitrary units of relative expression. In all assays, liquid controls and reactions without RT resulted in negative amplification.

RNA analysis by ISH. Hybridization analyses were conducted using specific sense and antisense NUCB2 riboprobes. Templates for riboprobe synthesis were generated by RT-PCR, following procedures similar to those of the previous section. Clamp polymerase sequences for T7 or T3 RNA polymerase were added to the $5^{\prime}$-end of the corresponding sense and antisense primers as follows: $r N e f$-ISH-forward (5'-CAG AGA TCC AAT TAA CCC TCA CTA AAG GGA GAC GCC AGA CAC GGG ACT TTA T-3'); rNef-ISH-reverse (5'-CCA AGC CTT CTA ATA CGA CTC ACT ATA GGG AGA GAT TCT GGT GGT TCA GGT GT-3'). Radiolabeled NUCB2 sense and antisense riboprobes were transcribed with T7 or T3 RNA polymerase (Promega). The riboprobes were separated from unincorporated nucleotides using NucAway Spin Columns (Ambion).

Slides with hypothalamic sections from the selected experimental groups were fixed in $4 \%$ paraformaldehyde, pretreated with acetic anhydride, rinsed in $2 \times$ sodium citrate, sodium chloride (SSC), delipidated in chloroform, dehydrated in graded ethanols, and then allowed to air dry before the hybridization. Riboprobes were denatured and dissolved in hybridization solution at a concentration of $0.1 \mathrm{pmol} / \mathrm{ml}$. The mix was heat denatured and added to prewarmed hybridization buffer, before application to each slide $(100 \mu \mathrm{l} / \mathrm{slide})$. The sections were then coverslipped and placed in humidity chambers at $55^{\circ} \mathrm{C}$ for $16 \mathrm{~h}$. After hybridization, the slides were washed in $4 \times$ SSC at room temperature and placed into $10 \mathrm{mg} / \mathrm{ml}$ RNase (Roche Biochemicals) for $30 \mathrm{~min}$ at $37^{\circ} \mathrm{C}$. After sequential washes at $2 \times \operatorname{SSC}(\mathrm{RT})$ and $0.1 \times \operatorname{SSC}\left(62^{\circ} \mathrm{C}\right)$, the sections were dehydrated, dipped in Kodak NTB emulsion, and stored at $4^{\circ} \mathrm{C}$ for $8-9 \mathrm{~d}$. Slides were then developed, dehydrated in graded eth anols, and cleared in Citrasol, and coverslips were applied with Permaslip (Sigma-Aldrich).

For quantitative analysis, all NUCB2 mRNA-containing sections were analyzed unilaterally. Slides from all of the animals were read under dark-field illumination with custom-designed software enabled to count the total number of cells (grain clusters) and the number of silver grains per cell (gpc). Cells were counted as NUCB2 mRNA positive when the number of silver grains in a cluster exceeded that of background. Thus, cell counts represent the number of cells that achieved detection threshold, whereas grains per NUCB2 cell reflect a semiQ index of mRNA content.

Brain ICC. Brain specimens were excised from pubertal (35-d-old) female rats immediately on decapitation of the animals $(n=5-6)$. The tissues were fixed in Bouin solution for $24 \mathrm{~h}$, and slabs containing the hypothalamus were processed for paraffin embedding. Six-micrometerthick sections were cut and processed for immunohistochemical detection of NUCB2/prepro-nesfatin, using a specific polyclonal antibody obtained from Phoenix (reference no. H-003-22). After dewaxing and rehydration in graded ethanol series, sections were incubated in $2 \%$ hydrogen peroxide in methanol for $30 \mathrm{~min}$ to inhibit endogenous peroxidase. After being washed in distilled water, sections were immersed in 10 $\mathrm{mm}$ citrate buffer and autoclaved at $1.5 \mathrm{~atm}$ for $3 \mathrm{~min}$. Thereafter, sections were allowed to cool at room temperature, washed in PBS, blocked with normal rabbit serum, and incubated overnight with the primary antibody (diluted 1:300). The sections were then processed according to the avidin-biotin peroxidase complex method, according to the manufacturer's instructions. Finally, sections were counterstained with hematoxylin. As control for specificity of ICC detection, ICC reactions were performed after preabsorption of the primary antiserum overnight at $4^{\circ} \mathrm{C}$ with nesfatin- 1 peptide (Phoenix). In addition, negative controls were run routinely in parallel by replacing the primary antibody by preimmune serum.

Protein analysis by Western blot. Hypothalamic total protein lysates (30 $\mu \mathrm{g}$ ) were subjected to SDS-PAGE on $10 \%$ polyacrylamide gels, and electrotransferred on polyvinylidene difluoride membrane (Millipore). Membranes were probed for $16 \mathrm{~h}$ at $4^{\circ} \mathrm{C}$ in the presence of a $1: 1000$ dilution of the primary antibody against rat NUCB2/Nesfatin-1. Protein detection was performed using horseradish peroxidase-conjugated secondary antibodies and enhanced chemiluminescence reagents (GE 
Healthcare). At least four hypothalami were used per group. The antiserum against rat NUCB2/prepro-nesfatin (reference no. H-003-22; Phoenix) was used. As internal control, tubulin protein content per lane was assayed using a similar protocol and primary rabbit antiserum (dilution, 1:10,000) against rat tubulin from Abcam.

NUCB2 as-MONs. Specific antisense MONs (Gene Tools) were designed to block NUCB2 translation by targeting the region surrounding or immediately upstream the ATG starting codon, as described in detail previously (Oh-I et al., 2006). Of note, two different as-MONs were designed: anti-NUCB2 MON-Ref ( $5^{\prime}$-CTC TGA AGA TGA GGT GGA GGA CCA T-3'), taken from a previous publication (Oh-I et al., 2006); and anti-NUCB2 MON-UCO (5'-TCA CAG ATG AGG CCA CTG AGA TCA G-3'), optimized for maximal suppression of translation according to the instructions of manufacturer. As control, a scramble oligonucleotide sequence ( $5^{\prime}$-CCT CTT ACC TCA GTT ACA ATT TAT A-3'), of similar composition but mixed order of bases, was infused to pair-aged female rats.

Hormone measurements. Serum LH and FSH levels were determined in a volume of 25-50 $\mu \mathrm{l}$ using a double-antibody method and radioimmunoassay kits supplied by the National Institutes of Health (Dr. A. F. Parlow, National Institute of Diabetes and Digestive and Kidney Diseases, National Hormone and Peptide Program, Torrance, CA). Rat LHI-10 and FSH-I-9 were labeled with ${ }^{125}$ I using IODO-GEN tubes, following the instructions of the manufacturer (Pierce). Hormone concentrations were expressed using reference preparations LH-RP-3 and FSH-RP-2 as standards. Intraassay and interassay coefficients of variation were $<8$ and $10 \%$ for $\mathrm{LH}$, and $<6$ and $9 \%$ for FSH, respectively. The sensitivity of the assay was $5 \mathrm{pg} /$ tube for $\mathrm{LH}$ and $20 \mathrm{pg} /$ tube for FSH. For each hormone, all samples were measures in the same assay. Accuracy of hormone determinations was confirmed by assessment of rat serum samples of known hormone concentrations.

Presentation of data and statistics. Hormone determinations were conducted in duplicate ( $n \geq 10$ samples/group). RT-PCR analyses were performed in duplicate from at least four to five RNA samples per group. Western blots were performed in duplicate ( $n \geq 4$ protein samples/ group). Hormonal and semiQ RNA data are presented as mean \pm SEM. Results were analyzed using Student's $t$ test or ANOVA followed by Student-Newman-Keuls multiple-range test (SigmaStat 2.0; SPSS). A value of $p \leq 0.05$ was considered significant.

\section{Results}

\section{Hypothalamic distribution of NUCB2/nesfatin mRNA} and protein at female puberty

The expression and anatomical distribution of NUCB2 mRNA, as well as of prepro-nesfatin protein, was qualitatively explored in the hypothalamus of female rats at the time of puberty, by a combination of ISH and ICC. Identification of the nuclei containing NUCB2/nesfatin-expressing neurons was done according to the L. W. Swanson rat brain atlas (Swanson, 2004). ISH assays demonstrated prominent staining of NUCB2 mRNA clusters, representing NUCB2-positive neurons, in the following hypothalamic nuclei: LHA, paraventricular nucleus (PVN/PVH), supraoptic nucleus (SON), and zona incerta (ZI). Additionally, scattered and fainter NUCB2 expression was observed also at the dorsomedial nucleus (DMN) and ARC (Fig. 1A,B). A close match between the patterns of mRNA expression and prepronesfatin distribution at the hypothalamus was detected, as our ICC assays detected clearly discernible, nesfatin-positive neurons at the LHA, PVN, and SON, with diffuse and weaker immunoreactivity being observed also at the ARC and, to a lesser extent, the DMN (Fig. 1C). Specificity of the above mRNA and protein determinations was demonstrated by the use of sense probes (ISH) and preabsorption of primary antibody (ICC), which yielded negative results (data not shown).

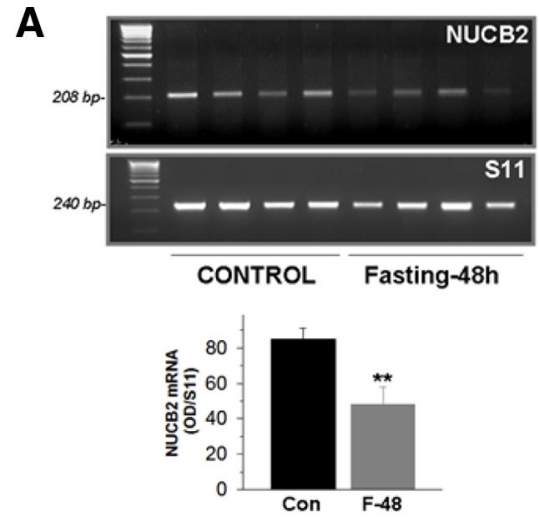

B NUCB2 (prepro-Nesfatin)

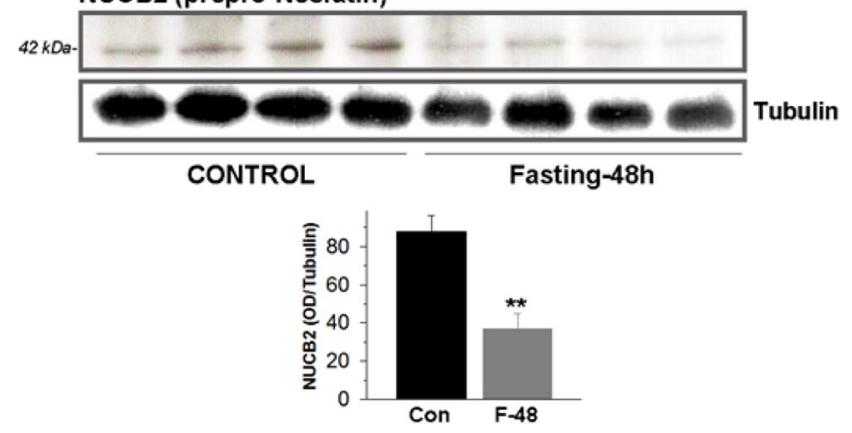

Figure 3. Effects of short-term fasting on hypothalamic expression of NUCB2 at puberty. In $A$, hypothalamic mRNA levels of NUCB2 in pubertal female rats either fed ad libitum [control (Con)] or fasted for $48 \mathrm{~h}$ (F-48). Representative RT-PCR assays and semiQ data (mean $\pm \mathrm{SEM} ; n \geq 4$ independent determinations, done in duplicate) are presented. In $\boldsymbol{B}$, hypothalamic NUCB2 protein levels at fed and fasted conditions are shown, with representative Western blots and semiQ data being presented. ${ }^{* *} p \leq 0.01$ versus control group (Student's $t$ test).

\section{Developmental and metabolic regulation of NUCB2 expression at puberty}

Based on the positive (neuroanatomical) detection of NUCB2/ nesfatin at the hypothalamus, putative changes of its mRNA and protein levels were explored along the pubertal transition and in conditions of metabolic stress, such as acute fasting and chronic food deprivation at puberty, by a combination of semiQ RT$\mathrm{PCR}, \mathrm{ISH}$, and Western blot. Of note, quantitative information about nucleus-specific NUCB2 mRNA levels was obtained by ISH analyses from the hypothalamic areas with the most prominent expression of this transcript, namely LHA, PVN (which extended partially to ZI), and SON. In contrast, because of the absence of clear cell clusters, such quantification was not possible at the ARC and DMN with our current software.

Although analysis of NUCB2 mRNA levels in whole hypothalamic fragments by semiQ RT-PCR failed to evidence any consistent changes between late infantile (20-d-old; BW, $30.4 \pm 1.8 \mathrm{~g}$ ) and pubertal (35-d-old; BW, $112.2 \pm 3.48 \mathrm{~g}$ ) female rats (data not shown), nucleus-specific ISH analyses did demonstrate an unambiguous, significant increase of NUCB2 mRNA levels at the LHA, PVN, and SON between these two ages (Fig. $2 A$ ). Yet the pattern of distribution of NUCB2 mRNA within the hypothalamus was grossly similar in infantile and pubertal females. The above quantitative changes in RNA profiles were in good agreement with the threefold increase in NUCB2 protein levels detected by Western blot during the pubertal transition (Fig. $2 \mathrm{~B}$ ). Of note, our protein analyses of hypothalamic tissue conducted using a primary antibody against rat nesfatin-1 consistently detected a single band of 

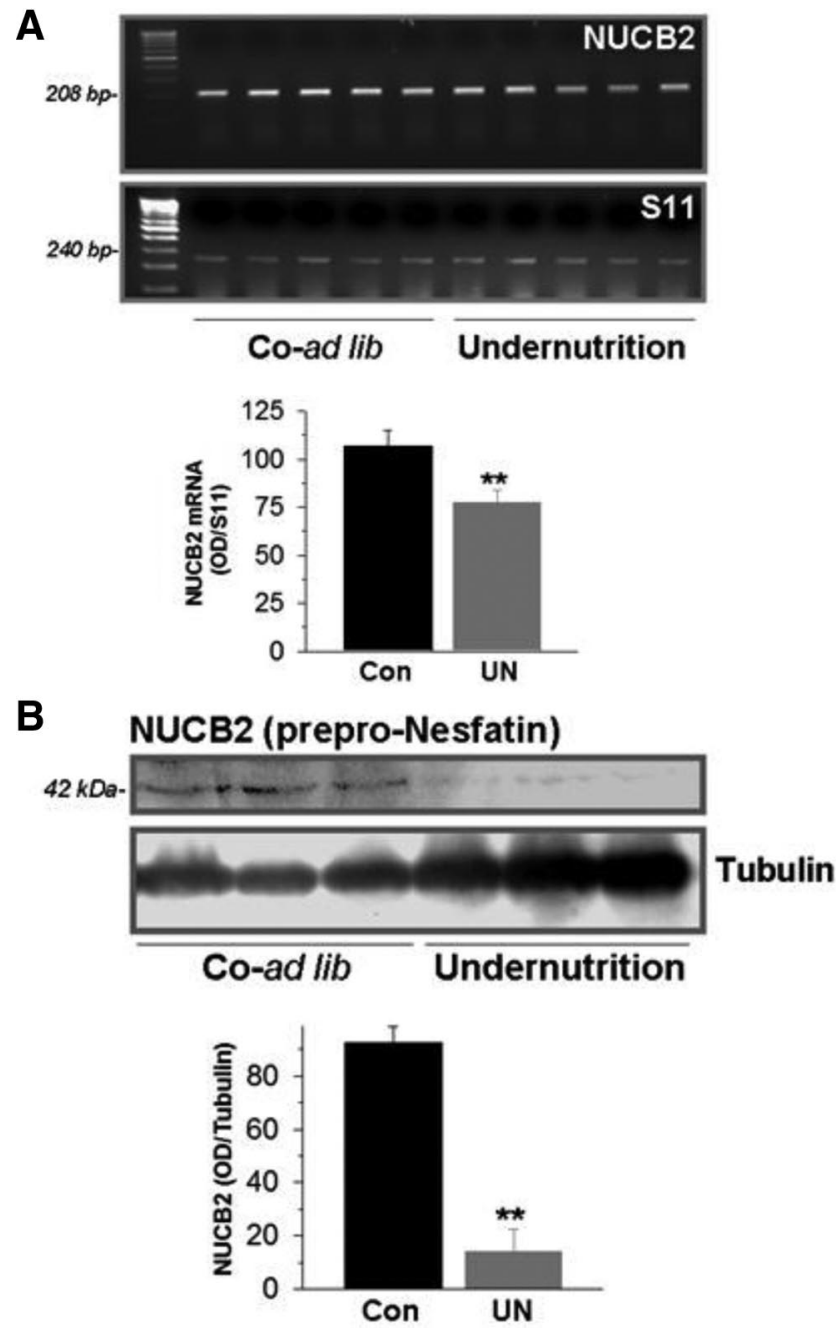

Figure 4. Effects of chronic undernutrition along puberty on hypothalamic expression of NUCB2. In $A$, hypothalamic mRNA levels of NUCB2 in pubertal OVX female rats, either fed ad libitum [Co-ad lib (Con)] or subjected to $25 \%$ reduction in daily food intake along puberty [Undernutrition (UN)]. Representative RT-PCR assays and semiQ data (mean \pm SEM; $n \geq 5$ independent determinations, done in duplicate) are presented. In $\boldsymbol{B}$, hypothalamic NUCB2 protein levels in fed and $25 \%$ food-restricted conditions are shown, with representative Western blots and semi $Q$ data being presented. ${ }^{* *} p \leq 0.01$ versus control group (Student's $t$ test).

$42 \mathrm{kDa}$, which appeared to correspond to NUCB2/prepronesfatin protein, according to its expected size and antibody data sheet (as provided by the manufacturer). In contrast, despite positive identification of synthetic nesfatin-1 (1-82) in our Western blot analyses (data not shown), no clearcut detection of such 82 aa peptide, of predicted $9.7 \mathrm{kDa}$ molecular weight, was observed in our protein assays of pubertal hypothalamic samples, in line with previous findings in different tissues from adult rats (Stengel et al., 2009).

Contrary to the observed increase in NUCB2 mRNA and peptide content along pubertal maturation, fasting for $48 \mathrm{~h}$ of pubertal female rats, which reduced body weight $(71.28 \pm 2.2$ vs $101.0 \pm 2.76 \mathrm{~g}$ in controls fed ad libitum), induced a decrease of relative NUCB2 mRNA levels, as evidenced by semiQ RT-PCR assays in whole hypothalamic fragments (Fig. $3 A$ ). Of note, however, our ISH assays failed to demonstrate any consistent change in NUCB2 mRNA expression at the hypothalamic nuclei with more prominent expression, namely LHA, PVN, and SON (data not shown). Notably, because of the absence of clear clusters of positive cells, ISH signals at DMN and ARC could not be quantified with our current software, thus leaving open the possibility
A

$A d-I i b$

Fast-48h

B
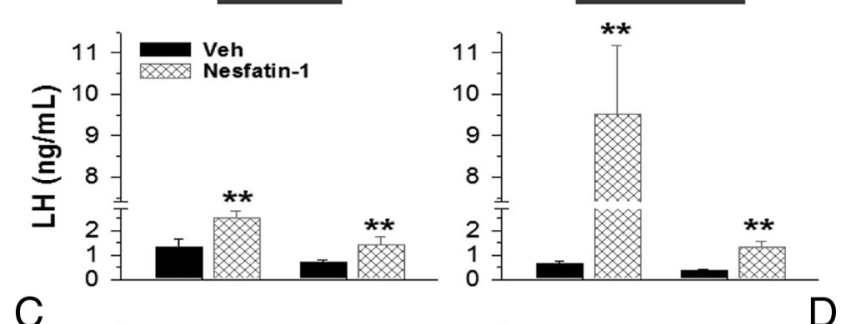

C
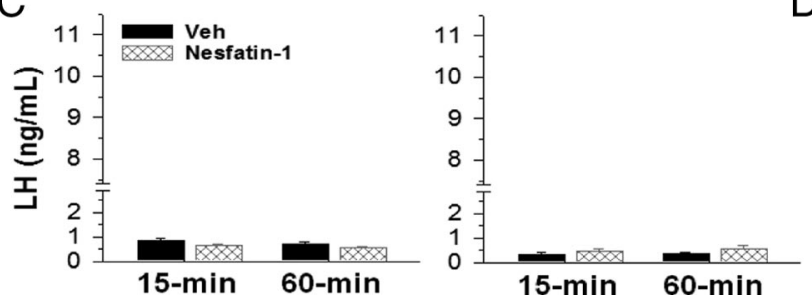

Figure 5. LH secretory responses to nesfatin-1 in pubertal female rats, at fed and fasting conditions. Serum LH concentrations at 15 and 60 min after intracerebroventricular injection of a single bolus ( $50 \mathrm{pmol} / \mathrm{rat}$ ) of nesfatin-1 or vehicle are shown. Tests were conducted in pubertal females, either fed ad libitum $(\boldsymbol{A})$ or fasted for $48 \mathrm{~h}$ before testing $(\boldsymbol{B})$. For comparative purposes, similar hormonal tests were conducted in adult female rats at metestrus, either at fed $(C)$ or $48 \mathrm{~h}$ fasting ( $\boldsymbol{D}$ ) conditions. Please note that the $y$-axis is broken at a certain range to allow proper representation of fed and fasted responses in pubertal animals with the same scale. ${ }^{* *} p \leq 0.01$ versus vehicle-injected group (ANOVA followed by Student-Newman-Keuls multiple-range test). Error bars indicate SEM.

of eventual changes in such areas of diffuse/weak expression of NUCB2. In any event, the decrease in relative NUCB2 mRNA levels, as detected by semiQ RT-PCR, was associated with a marked reduction in NUCB2 protein content in hypothalamic tissue (Fig. 3B). Likewise, chronic undernutrition along puberty, which overtly decreased body weight gain $(80.18 \pm 1.87$ vs $99.2 \pm$ $2.59 \mathrm{~g}$ in animals fed ad libitum, at day 36 postpartum) induced a significant $\sim 30 \%$ decrease in NUCB2 mRNA levels (Fig. $4 A$ ), and resulted in a dramatic $>80 \%$ drop of NUCB2 protein content at the hypothalamus (Fig. 4B). Noteworthy, sustained food restriction during puberty was applied to OVX rats, to avoid the potential confounding factor of dynamic fluctuations in endogenous levels of sex steroids because of persistent food deprivation.

\section{Effects of nesfatin-1 on gonadotropin secretion at puberty} and adulthood

In addition to expression analyses of NUCB2, gonadotropin responses to nesfatin- 1 were explored in pubertal female rats, in fed and fasting conditions. For comparative purposes, similar experiments were also conducted in adult, cyclic female rats. As shown in Figure $5 A$, intracerebroventricular injection of $50 \mathrm{pmol} / \mathrm{rat}$ nesfatin-1 evoked a significant rise of circulating LH levels that peaked at $15 \mathrm{~min}$ (twofold increase over controls injected with vehicle) and remained elevated at $60 \mathrm{~min}$ after injection. Similarly, FSH levels at $15 \mathrm{~min}$ after intracerebroventricular administration of nesfatin- 1 were elevated $(5.29 \pm 1.3$ vs $2.67 \pm 0.45$ $\mathrm{ng} / \mathrm{ml}$ in vehicle-injected animals), although this difference fell shortly below the limit of statistical significance $(p<0.07)$. Despite the prevailing lowering of its circulating levels $(0.65 \pm 0.12$ vs $1.32 \pm 0.31 \mathrm{ng} / \mathrm{ml}$ in controls fed ad libitum), fasting for $48 \mathrm{~h}$ significantly augmented the magnitude of LH responses to intracerebroventricular injection of nesfatin-1. Thus, a ninefold elevation of serum LH levels was observed at 15 min after nesfatin-1 administration to fasted female rats (Fig. 5B). Likewise, net FSH responses to nesfatin-1 (at $15 \mathrm{~min}$ ) were also increased in females 
A
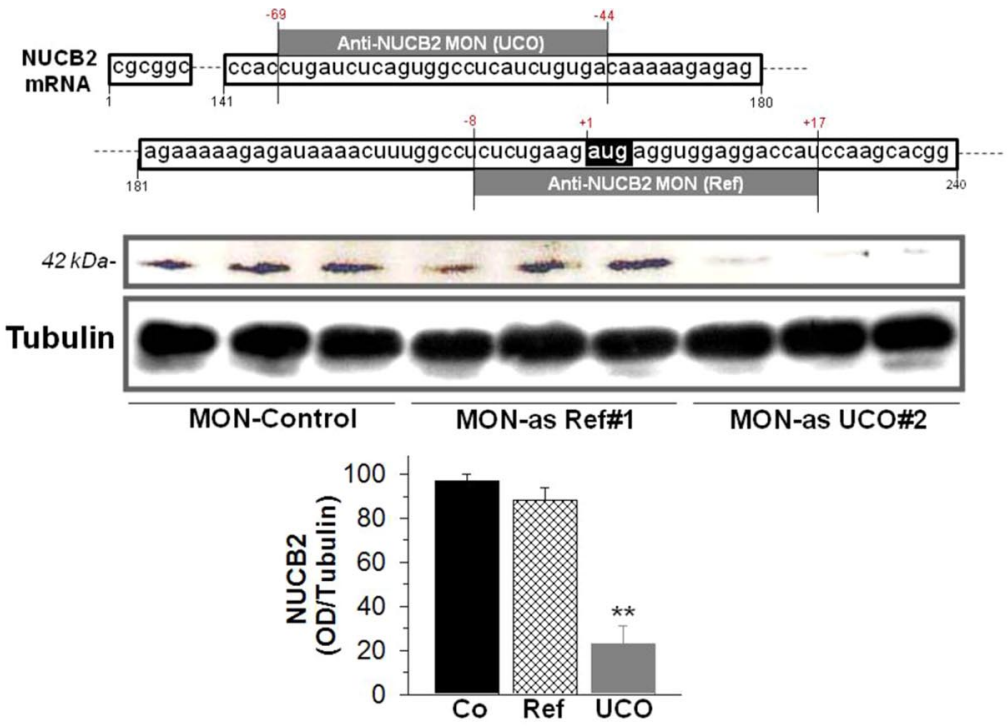

B
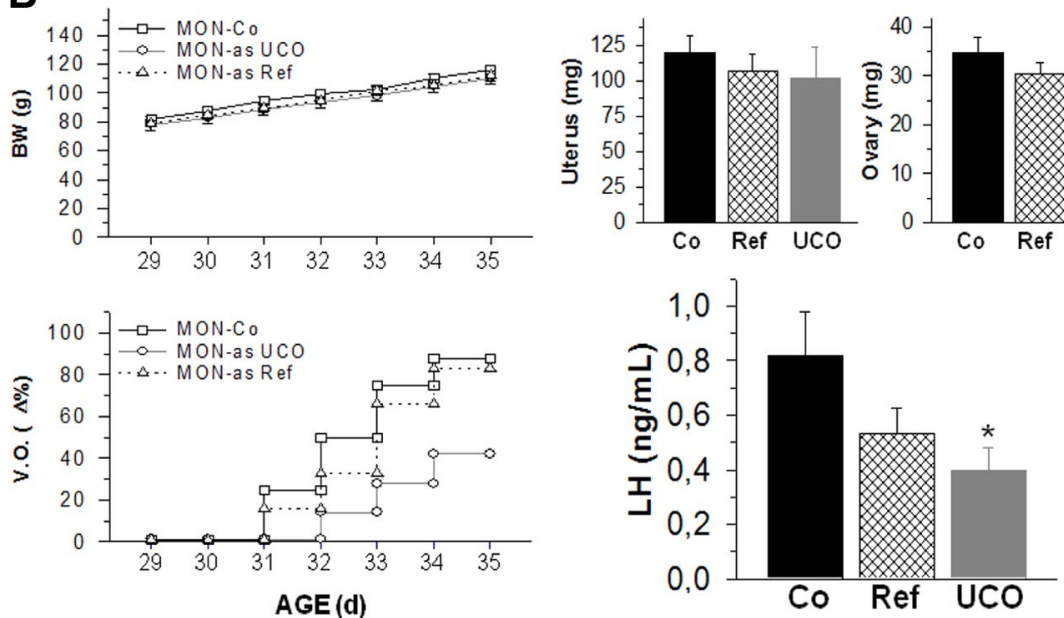

Figure 6. Knockdown of hypothalamic NUCB2/nesfatin-1 and puberty onset in the female rat. In $\boldsymbol{A}$, the design and in vivo efficiency of anti-NUCB2 morpholino oligonucleotides (as-MONs) is presented. The sequence and relative position (relative to ATG start codon) are shown for the two anti-NUCB2 MON used in this study: as-MON Ref, taken for a previous reference (Oh-l et al., 2006), and the newly designed anti-as-MON UCO. In addition, hypothalamic NUCB2 protein contents in groups of females infused with either anti-as-MON Ref or UCO, as well as in control rats infused with a scramble oligonucleotide, are presented as representative Western blots and semiQ data. ${ }^{* *} p \leq 0.01$ versus control group (ANOVA followed by Student-Newman-Keuls multiplerange test). In $\boldsymbol{B}$, the impact of chronic intracerebroventricular infusion of as-MONs to pubertal female rats (between day 28 and day 35) on different indices of puberty onset is documented. Body weights (BW), vaginal opening (V.0.), uterus and ovarian weights, and terminal serum LH levels are presented for the three experimental groups: (1) controls (Co) infused with scramble oligonucleotide, (2) females infused with as-MON Ref, and (3) rats infused with as-MON UCO. ${ }^{*} p \leq 0.05$ versus control group (ANOVA followed by Student-Newman-Keuls multiple-range test). Error bars indicate SEM.

subjected to $48 \mathrm{~h}$ fasting $(7.99 \pm 1.18$ vs $5.29 \pm 1.3 \mathrm{ng} / \mathrm{ml}$ in nonfasted controls injected with nesfatin-1). In clear contrast, LH levels in cyclic female rats at metestrus failed to raise after intracerebroventricular injection of nesfatin-1, either in fed or fasting conditions (Fig. 5C,D). Likewise, nesfatin-1 did not modify circulating FSH levels in adult females, at none of the time points (15 and $60 \mathrm{~min}$ ) and conditions (fed ad libitum and $48 \mathrm{~h}$ fasting) tested (data not shown).

Inhibition of NUCB2/nesfatin-1 delays puberty onset

To assess the functional relevance of NUCB2/nesfatin-1 in the central control of puberty onset, an in vivo antisense MON approach was applied, following previous references (Oh-I et al., 2006). To achieve a maximal degree of NUCB2 suppression, two different as-

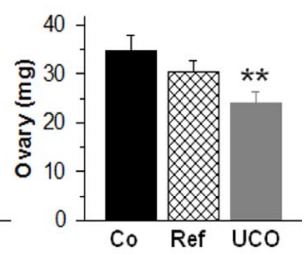

MONs were independently tested for intracerebroventricular infusion along the pubertal transition: (1) anti-NUCB2 MON Ref, which was synthesized as described previously (Oh-I et al., 2006), surrounding the ATG start codon (position -8 to +17$)$; and (2) anti-NUCB2 MON UCO, which targeted a $5^{\prime}$-end region upstream of the ATG codon (position - 69 to -44 ), to enhance interference of NUCB2 translation, as recommended by the manufacturer. After completion of protocols of $7 \mathrm{~d}$ intracerebroventricular infusion, NUCB2 protein contents were assayed at the hypothalamus; Western blots revealed that, whereas as-MON Ref evoked only a marginal decrease in NUCB2 protein content, central administration of as-MON UCO induced a dramatic suppression of the peptide levels at the hypothalamus that dropped to nearly $20 \%$ of control values in females infused with scrambled oligos (Fig. 6A).

In this model, phenotypic and hormonal analyses were applied to monitor progression of puberty. Infusion of any of the two anti-NUCB2 MON failed to induce overt changes in terms of body weight gain (Fig. 6B), or daily food intake (data not shown), along treatment. However, intracerebroventricular administration of MON against NUCB2 induced a delay in the timing of puberty, with a much greater effect in terms of later occurrence of vaginal opening being observed in females infused with as-MON UCO (Fig. 6B), a phenomenon that narrowly paralleled the decrease in hypothalamic NUCB2 protein levels. In good agreement, treatment with this as-MON induced a significant reduction in terminal ovarian weights; a slight trend toward decrease in uterus weight was also observed but did not reach significance because of high variability among samples (Fig. 6B). Finally, chronic infusion with anti-NUCB2 MON resulted also in the lowering of circulating LH levels at the end of the treatment, a phenomenon that was of higher magnitude and reached statistical significance in pubertal females infused with anti-NUCB2 MON UCO (Fig. 6B).

\section{Inhibition of NUCB2/nesfatin-1 fails to alter gonadotropin surges in adult females}

Given its predicted role in puberty (see above), the impact of knocking down hypothalamic expression of NUCB2/nesfatin-1 on gonadotropic function was also explored in adult, cyclic female rats. A protocol of as-MON infusion, using anti-NUCB2 MON UCO, similar to that applied to pubertal rats, was implemented. As was the case for immature animals, hypothalamic NUCB2 protein contents were markedly decreased ( $\sim 75 \%$ reduction) after central administration of anti-NUCB2 MON for $7 \mathrm{~d}$ (Fig. 7A). Neither body weight gain nor daily food intake was 
A

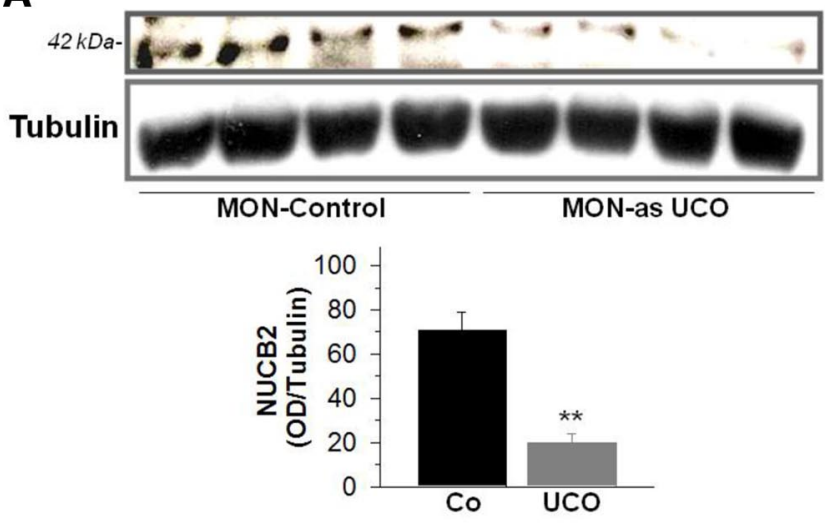

B
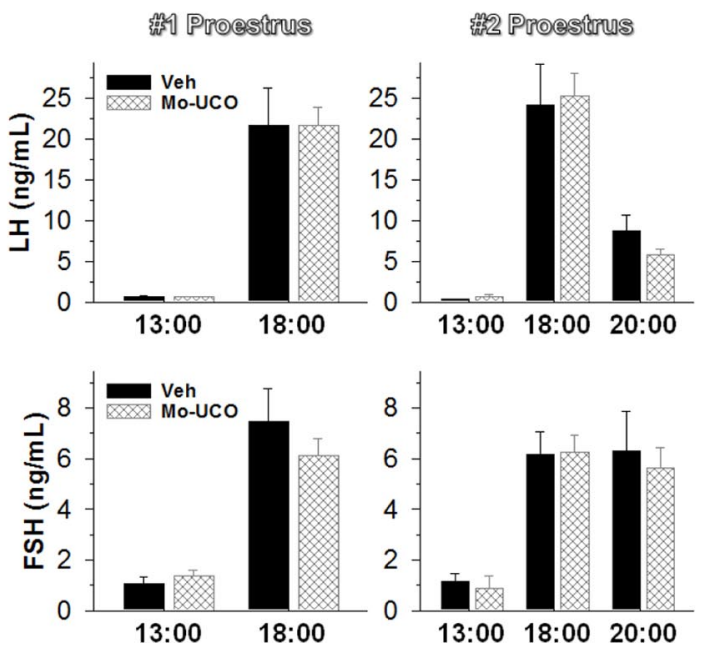

Figure 7. Knockdown of hypothalamic NUCB2/nesfatin-1 and preovulatory surges in the cyclic rat. In $\boldsymbol{A}$, hypothalamic NUCB2 protein contents in groups of females infused with either as-MON UCO or a scramble oligonucleotide (controls) are presented, with representative Western blots and semiQ data being shown. ${ }^{* *} p \leq 0.01$ versus control group (ANOVA followed by Student-Newman-Keuls multiple-range test). In $\boldsymbol{B}$, the lack of impact of chronic intracerebroventricular infusion of anti-NUCB2 MON UCO to adult female rats during two consecutive cycles is documented. During this time period, LH and FSH levels at the afternoon/evening of the corresponding proestrus ( 1 and 2) were monitored in control animals $\left(\mathrm{C}_{0}\right)$ infused with a scramble oligonucleotide and rats treated with as-MON UCO. Error bars indicate SEM.

overtly altered by this protocol of as-MON infusion (data not shown). Moreover, vaginal estrous cyclicity was grossly preserved during the infusion period in anti-NUCB2 MON-treated females, which also displayed conserved preovulatory $\mathrm{LH}$ and $\mathrm{FSH}$ surges. Thus, blood sampling at the afternoon/evening of each proestrus during the treatment (two phases, $4 \mathrm{~d}$ apart) demonstrated that the magnitude of $\mathrm{LH}$ and FSH peaks was similar between controls and female rats intracerebroventricularly infused with as-MONs (Fig. 7B).

\section{Discussion}

NUCB2/nesfatin-1 has recently emerged as appetite-suppressing signal, presumably acting at key hypothalamic and brainstem centers, in a leptin-independent manner (Oh-I et al., 2006; Shimizu et al., 2009). Our current expression and functional data strongly suggest that, in addition, this novel neuropeptide system is involved in the stimulatory control of the gonadotropic axis at puberty in the female rat, a function that may contribute to the central coupling of reproductive maturation and the energy reserves of the organism.
This study is the first to provide a detailed neuroanatomical characterization of NUCB2/prepro-nesfatin distribution in the hypothalamus at the time of puberty. Our present data are in agreement with the hypothalamic location of NUCB2 mRNA originally reported in adult male rats (Oh-I et al., 2006), with prominent signals being detected in the LHA (which expanded toward ZI), followed by PVH, SON, and, at lesser intensity, ARC and DMN, the latter not being observed in adult animals. Yet, despite this conserved pattern of distribution, our expression analyses in pubertal animals demonstrated that hypothalamic NUCB2 mRNA/protein levels are under the control of developmental cues, as NUCB2 mRNA levels significantly raised at LHA, $\mathrm{PVN}$, and SON, and total prepro-nesfatin content increased by threefold, along the transition between late-infantile and peripubertal periods. The functional relevance of such developmental activation of nesfatin system in the timing of puberty is reinforced by our pharmacological and functional knockdown data (see below).

In addition to developmental cues, conditions of negative energy balance, coupled to suppressed gonadotropin secretion and/or puberty onset, were associated also to detectable changes of NUCB2 expression. Thus, short-term fasting resulted in reductions of NUCB2 mRNA and protein levels at the hypothalamus of pubertal rats. Of note, however, our ISH analyses failed to detect significant variations in NUCB2 mRNA expression at the LHA, PVN, and SON, thus indirectly suggesting that these changes (as measured by semiQ RT-PCR) may take place at other nuclei, such as the ARC, where the fainter and scattered pattern of distribution of the signal hampered reliable quantifications by ISH. Likewise, hypothalamic NUCB2 mRNA and protein levels were consistently reduced by a protocol of chronic undernutrition (25\% daily food restriction) along the pubertal transition. Altogether, the above findings are compatible with a potential positive role of NUCB2/nesfatin-1 signaling in the activation of the gonadotropic axis at puberty, although the populations of nesfatin neurons sensitive to developmental and metabolic cues seem to be different. Also of interest, our protein analyses did not detect mature nesfatin-1 peptide in whole hypothalamic fragments, in line with previous observations in rat brain and peripheral tissues, a finding that might suggest a postsecretory cleavage/ regulation of NUCB2 (Stengel et al., 2009), which remains so far unexplored.

The functional involvement of NUCB2/nesfatin-1 in the positive control of the gonadotropic axis at puberty was further evidenced by our acute pharmacological tests, which demonstrated that intracerebral injection of nesfatin-1 elicited a modest but detectable elevation of LH and, to a lesser extent, FSH levels in pubertal females fed ad libitum. Of interest, gonadotropin responses to nesfatin-1 were dramatically augmented after $48 \mathrm{~h}$ fasting, despite the prevailing decrease in circulating LH levels. This observation is compatible with a predominant permissive action of nesfatin-1 in gonadotropin control. Thus, in normal metabolic conditions, responses to exogenous nesfatin are modest, but these are exacerbated by the prevailing reduction of its endogenous tone after food deprivation, a phenomenon that has been previously documented for other gonadotropin secretagogues (Castellano et al., 2005, 2009b).

The above biological profile (i.e., permissive role) prompted us to address the relevance of nesfatin signaling in the timing of puberty by the use of knocking-down strategies in vivo. Our asMON approach provided strong support for an essential, indispensable role of NUCB2/nesfatin-1 signaling in the control of female puberty, since knocking down of NUCB2 levels at the 
hypothalamus was tightly coupled to significantly delayed puberty onset, as evidenced by conventional phenotypic and hormonal indices. Admittedly, however, occurrence of first estrus could not be monitored in our experiments because of the lack of vaginal opening in the majority of as-MON infused animals. Two different as-MONs, with different efficiencies in terms of NUCB2 suppression, were applied, with a close match being detected between the degree of inhibition of hypothalamic expression of NUCB2 and the impact in terms of timing of puberty. This observation, together with the fact that control females (which displayed normal puberty) were infused with a scrambled MON, rule out the possibility of a spurious, nonspecific effect of our approach in terms of puberty disruption. Also of interest, despite effective suppression of NUCB2 at the hypothalamus, no significant effects in terms of body weight gain or daily food intake were detected in our experiments. This may be attributable to the fact that puberty is a developmental stage when body growth is set at maximal speed, a situation that may obscure subtle actions of a given neuropeptide on the above metabolic parameters. In any event, comparison of the effects of NUCB2 knockdown in terms of body weight (lack of effect) and reproductive maturation (suppression) makes it tenable to propose that the degree of redundancy is higher for appetite-controlling networks (as indispensable function for individual survival) than for those governing puberty (a dispensable phenomenon in periods of adverse energy conditions).

In contrast to pubertal females, exogenous administration of nesfatin-1 did not cause any detectable changes in the circulating levels of gonadotropins in adult, cyclic female rats. In good agreement, suppression of hypothalamic NUCB2 failed to overtly affect a hallmark index of adult gonadotropic function in the female, namely the preovulatory surges of gonadotropins, despite the fact that the overall reduction of prepro-nesfatin-1 levels induced by as-MON infusion was grossly similar to that evoked in immature females. Although the possibility that blockade of NUCB2 translation was insufficient at key hypothalamic nuclei cannot be completely excluded, these observations strongly suggest that, in contrast to our observations at puberty, nesfatin signaling seems less critical (if not totally dispensable) for the occurrence of $\mathrm{LH}$ and FSH preovulatory surges. These findings point out substantial developmental differences in the relative importance of NUCB2/nesfatin-1 in the neuroendocrine control of the female gonadotropic axis. Intriguingly, our protocols of (effective) knocking-down of NUCB2 at the hypothalamus did not cause major detectable changes in daily food intake or body weight gain in adult female rats, in contrast with previous data in adult male rats and mice (Oh-I et al., 2006; Shimizu et al., 2009). These observations may suggest a more prominent role of nesfatin signaling in the control of feeding in male rodents, in keeping with recent reports (Xu et al., 2009). In this context, the potential role of this neuropeptide in the control of male puberty and gonadotropic function warrants additional investigation.

Admittedly, despite our present data, characterization of the specific neuroendocrine mechanisms and pathways whereby nesfatin-1 regulates the gonadotropic axis at puberty remain to be completed, and will require additional neuroanatomical (e.g., quantitative ICC and colocalization techniques) and functional analyses. Nonetheless, nesfatin-1 is known to be expressed in hypothalamic areas primarily involved in the control of reproduction, and NUCB2-positive neurons have been shown to coexpress and/or regulate different neuropeptide systems with proven roles in the central regulation of reproductive function (Oh-I et al., 2006; Brailoiu et al., 2007; Foo et al., 2008; Price et al.,
2008). On the latter, the ability of nesfatin-1 to stimulate oxytocin release at PVN has been recently demonstrated (Maejima et al., 2009), oxytocin being a positive regulator of female pubertal maturation (Parent et al., 2008). In addition, the potential interplay of NUCB2 neuronal pathways with other key regulators of the gonadotropin-releasing hormone/gonadotropic axis, as the recently discovered kisspeptin system (Roa et al., 2008a), merits specific investigation. Intriguingly, colocalization of NUCB2 and phosphor-mammalian target of rapamycin (mTOR) has been very recently described in discrete neuronal populations at the hypothalamus (Inhoff et al., 2010), mTOR being a putative regulator of Kiss1 gene expression (Roa et al., 2009). Finally, as the effects of nesfatin-1 on food intake have been proposed as leptinindependent (Oh-I et al., 2006; Shimizu et al., 2009), it will be interesting to explore whether NUCB2/nesfatin signaling might also participate in mediating the influence of metabolic signals other than leptin on puberty onset and gonadotropin secretion.

In sum, our data are the first to substantiate the putative reproductive roles of NUCB2/nesfatin-1 as essential regulator of the gonadotropic axis at puberty in the female rat. In contrast, hypothalamic nesfatin signaling seems to be dispensable for the generation of the preovulatory surges of gonadotropins in the adult, cyclic female. Present results expand our current knowledge on the neuroendocrine signals responsible for the control of puberty onset and its eventual coupling with energy homeostasis, and contribute to the characterization of the whole spectrum of biological actions of nesfatin-1 as potential therapeutic target in the management of body weight disorders.

\section{References}

Berthoud HR, Morrison C (2008) The brain, appetite, and obesity. Annu Rev Psychol 59:55-92.

Brailoiu GC, Dun SL, Brailoiu E, Inan S, Yang J, Chang JK, Dun NJ (2007) Nesfatin-1: distribution and interaction with a $G$ protein-coupled receptor in the rat brain. Endocrinology 148:5088-5094.

Castellano JM, Navarro VM, Fernández-Fernández R, Nogueiras R, Tovar S, Roa J, Vazquez MJ, Vigo E, Casanueva FF, Aguilar E, Pinilla L, Dieguez C, Tena-Sempere M (2005) Changes in hypothalamic KiSS-1 system and restoration of pubertal activation of the reproductive axis by kisspeptin in undernutrition. Endocrinology 146:3917-3925.

Castellano JM, Navarro VM, Fernández-Fernández R, Roa J, Vigo E, Pineda R, Dieguez C, Aguilar E, Pinilla L, Tena-Sempere M (2006) Expression of hypothalamic KiSS-1 system and rescue of defective gonadotropic responses by kisspeptin in streptozotocin-induced diabetic male rats. Diabetes 55:2602-2610.

Castellano JM, Roa J, Luque RM, Dieguez C, Aguilar E, Pinilla L, TenaSempere M (2009a) KiSS-1/kisspeptins and the metabolic control of reproduction: physiologic roles and putative physiopathological implications. Peptides 30:139-145.

Castellano JM, Navarro VM, Roa J, Pineda R, Sánchez-Garrido MA, GarcíaGaliano D, Vigo E, Dieguez C, Aguilar E, Pinilla L, Tena-Sempere M (2009b) Alterations in hypothalamic KiSS-1 system in experimental diabetes: early changes and functional consequences. Endocrinology 150:784-794

Colmers WF (2007) Less fat with nesfatin. Trends Endocrinol Metab $18: 131-132$.

Crowley VE (2008) Overview of human obesity and central mechanisms regulating energy homeostasis. Ann Clin Biochem 45:245-255.

Fernandez-Fernandez R, Martini AC, Navarro VM, Castellano JM, Dieguez C, Aguilar E, Pinilla L, Tena-Sempere M (2006) Novel signals for the integration of energy balance and reproduction. Mol Cell Endocrinol 254-255:127-132.

Foo KS, Brismar H, Broberger C (2008) Distribution and neuropeptide coexistence of nucleobindin-2 mRNA/nesfatin-like immunoreactivity in the rat CNS. Neuroscience 156:563-579.

Fort P, Salvert D, Hanriot L, Jego S, Shimizu H, Hashimoto K, Mori M, Luppi PH (2008) The satiety molecule nesfatin-1 is co-expressed with melanin 
concentrating hormone in tuberal hypothalamic neurons of the rat. Neuroscience 155:174-181.

Goebel M, Stengel A, Wang L, Lambrecht NW, Taché Y (2009) Nesfatin-1 immunoreactivity in rat brain and spinal cord autonomic nuclei. Neurosci Lett 452:241-246.

Hill JW, Elmquist JK, Elias CF (2008) Hypothalamic pathways linking energy balance and reproduction. Am J Physiol Endocrinol Metab 294: E827-E832.

Inhoff T, Stengel A, Peter L, Goebel M, Taché Y, Bannert N, Wiedenmann B, Klapp BF, Mönnikes H, Kobelt P (2010) Novel insight in distribution of nesfatin- 1 and phospho-mTOR in the arcuate nucleus of the hypothalamus of rats. Peptides 31:257-262.

Kalra SP, Dube MG, Pu S, Xu B, Horvath TL, Kalra PS (1999) Interacting appetite-regulating pathways in the hypothalamic regulation of body weight. Endocr Rev 20:68-100.

Kohno D, Nakata M, Maejima Y, Shimizu H, Sedbazar U, Yoshida N, Dezaki K, Onaka T, Mori M, Yada T (2008) Nesfatin-1 neurons in paraventricular and supraoptic nuclei of the rat hypothalamus coexpress oxytocin and vasopressin and are activated by refeeding. Endocrinology 149: $1295-1301$.

Maejima Y, Sedbazar U, Suyama S, Kohno D, Onaka T, Takano E, Yoshida N, Koike M, Uchiyama Y, Fujiwara K, Yashiro T, Horvath TL, Dietrich MO, Tanaka S, Dezaki K, Oh-I S, Hashimoto K, Shimizu H, Nakata M, Mori M, et al. (2009) Nesfatin-1-regulated oxytocinergic signaling in the paraventricular nucleus causes anorexia through a leptin-independent melanocortin pathway. Cell Metab 10:355-365.

Myers MG Jr (2006) Keeping the fat off with nesfatin. Nat Med 12: $1248-1249$

Navarro VM, Castellano JM, Fernández-Fernández R, Barreiro ML, Roa J, Sanchez-Criado JE, Aguilar E, Dieguez C, Pinilla L, Tena-Sempere M (2004a) Developmental and hormonally regulated messenger ribonucleic acid expression of KiSS-1 and its putative receptor, GPR54, in rat hypothalamus and potent luteinizing hormone-releasing activity of KiSS-1 peptide. Endocrinology 145:4565-4574.

Navarro VM, Fernández-Fernández R, Castellano JM, Roa J, Mayen A, Barreiro ML, Gaytan F, Aguilar E, Pinilla L, Dieguez C, Tena-Sempere M (2004b) Advanced vaginal opening and precocious activation of the reproductive axis by KiSS-1 peptide, the endogenous ligand of GPR54. J Physiol 561:379-386.

Oh-I S, Shimizu H, Satoh T, Okada S, Adachi S, Inoue K, Eguchi H, Yamamoto M, Imaki T, Hashimoto K, Tsuchiya T, Monden T, Horiguchi K, Yamada M, Mori M (2006) Identification of nesfatin-1 as a satiety molecule in the hypothalamus. Nature 443:709-712.

Parent AS, Rasier G, Matagne V, Lomniczi A, Lebrethon MC, Gérard A, Ojeda SR, Bourguignon JP (2008) Oxytocin facilitates female sexual maturation through a glia-to-neuron signaling pathway. Endocrinology 149: $1358-1365$.
Price CJ, Samson WK, Ferguson AV (2008) Nesfatin-1 inhibits NPY neurons in the arcuate nucleus. Brain Res 1230:99-106.

Roa J, Aguilar E, Dieguez C, Pinilla L, Tena-Sempere M (2008a) New frontiers in kisspeptin/GPR54 physiology as fundamental gatekeepers of reproductive function. Front Neuroendocrinol 29:48-69.

Roa J, Vigo E, Castellano JM, Gaytan F, Navarro VM, Aguilar E, Dijcks FA, Ederveen AG, Pinilla L, van Noort PI, Tena-Sempere M (2008b) Opposite roles of estrogen receptor (ER)-alpha and ERbeta in the modulation of luteinizing hormone responses to kisspeptin in the female rat: implications for the generation of the preovulatory surge. Endocrinology 149: $1627-1637$.

Roa J, Vigo E, García-Galiano D, Castellano JM, Navarro VM, Pineda R, Diéguez C, Aguilar E, Pinilla L, Tena-Sempere M (2008c) Desensitization of gonadotropin responses to kisspeptin in the female rat: analyses of LH and FSH secretion at different developmental and metabolic states. Am J Physiol Endocrinol Metab 294:E1088-E1096.

Roa J, Vigo E, Castellano JM, Gaytan F, García-Galiano D, Navarro VM, Aguilar E, Dijcks FA, Ederveen AG, Pinilla L, van Noort PI, Tena-Sempere M (2008d) Follicle-stimulating hormone responses to kisspeptin in the female rat at the preovulatory period: modulation by estrogen and progesterone receptors. Endocrinology 149:5783-5790.

Roa J, Garcia-Galiano D, Varela L, Sánchez-Garrido MA, Pineda R, Castellano JM, Ruiz-Pino F, Romero M, Aguilar E, López M, Gaytan F, Diéguez C, Pinilla L, Tena-Sempere M (2009) The mammalian target of rapamycin as novel central regulator of puberty onset via modulation of hypothalamic Kiss1 system. Endocrinology 150:5016-5026.

Shimizu H, Oh-I S, Hashimoto K, Nakata M, Yamamoto S, Yoshida N, Eguchi H, Kato I, Inoue K, Satoh T, Okada S, Yamada M, Yada T, Mori M (2009) Peripheral administration of nesfatin-1 reduces food intake in mice: the leptin-independent mechanism. Endocrinology 150:662-671.

Stengel A, Goebel M, Yakubov I, Wang L, Witcher D, Coskun T, Taché Y, Sachs G, Lambrecht NW (2009) Identification and characterization of nesfatin-1 immunoreactivity in endocrine cell types of the rat gastric oxyntic mucosa. Endocrinology 150:232-238.

Swanson LW (2004) Brain maps III: structure of the rat brain. San Diego: Elsevier.

Woods SC, D’Alessio DA (2008) Central control of body weight and appetite. J Clin Endocrinol Metab 93:S37-S50.

Xu L, Bloem B, Gaszner B, Roubos EW, Kozicz T (2009) Sex-specific effects of fasting on urocortin 1 , cocaine- and amphetamine-regulated transcript peptide and nesfatin-1 expression in the rat Edinger-Westphal nucleus. Neuroscience 162:1141-1149.

Yosten GL, Samson WK (2009) Nesfatin-1 exerts cardiovascular actions in brain: possible interaction with the central melanocortin system. Am J Physiol Regul Integr Comp Physiol 297:R330-R336. 